\title{
Overexpression of YWHAZ relates to tumor cell proliferation and malignant outcome of gastric carcinoma
}

\author{
Y Nishimura ${ }^{1,3}$, S Komatsu ${ }^{1,3}$, D Ichikawa ${ }^{1}$, H Nagata ${ }^{1}$, S Hirajima ${ }^{1}$, H Takeshita ${ }^{1}$, T Kawaguchi ${ }^{1}$, T Arita $^{1}$, \\ H Konishi ${ }^{1}$, K Kashimoto ${ }^{1}$, A Shiozaki ${ }^{1}$, H Fujiwara ${ }^{1}$, K Okamoto ${ }^{1}, \mathrm{H}_{\text {Tsuda }}{ }^{2}$ and E Otsuji ${ }^{1}$ \\ ${ }^{1}$ Division of Digestive Surgery, Department of Surgery, Kyoto Prefectural University of Medicine, 465 Kajii-cho, Kawaramachihirokoji, \\ Kamigyo-ku, Kyoto 602-8566, Japan and 2Department of Pathology, National Cancer Center Hospital, Tokyo, Japan
}

Background: Several studies have demonstrated that YWHAZ (14-3-3ఢ), included in the 14-3-3 family of proteins, has been implicated in the initiation and progression of cancers. We tested whether YWHAZ acted as a cancer-promoting gene through its activation/overexpression in gastric cancer (GC).

Methods: We analysed 7 GC cell lines and 141 primary tumours, which were curatively resected in our hospital between 2001 and 2003.

Results: Overexpression of the YWHAZ protein was frequently detected in GC cell lines (six out of seven lines, 85.7\%) and primary tumour samples of GC (72 out of 141 cases, $51 \%$ ), and significantly correlated with larger tumour size, venous and lymphatic invasion, deeper tumour depth, and higher pathological stage and recurrence rate. Patients with YWHAZ-overexpressing tumours had worse overall survival rates than those with non-expressing tumours in both intensity and proportion expression-dependent manner. YWHAZ positivity was independently associated with a worse outcome in multivariate analysis $(P=0.0491$, hazard ratio 2.3 (1.003-5.304)). Knockdown of YWHAZ expression using several specific siRNAs inhibited the proliferation, migration, and invasion of YWHAZ-overexpressing GC cells. Higher expression of the YWHAZ protein was significantly associated with the lower expression of miR-375 in primary GC tissues $(P=0.0047)$.

Conclusion: These findings suggest that YWHAZ has a pivotal role in tumour cell proliferation through its overexpression, and highlight its usefulness as a prognostic factor and potential therapeutic target in GC.

Gastric cancer is the second leading cause of cancer-related deaths in the world (Parkin et al, 2005). Recent advances in diagnostic techniques and peri-operative management have increased early detection of gastric cancer and decreased the mortality rate. However, patients with advanced disease still frequently develop recurrent disease after extended radical resections, and consequently have extremely poor survival rates (Martin et al, 2002).

Many genes have been analysed in an attempt to understand the molecular mechanisms of human gastric cancers and improve its clinical outcomes; however, only a few with frequent alterations have been identified (Ushijima and Sasako, 2004). Oncogenic activation of $\beta$-catenin and K-ras (Park et al, 1999; Lee et al, 2002), amplifications of MET and ERBB2, mutations of TP53, APC, and E-cadherin (Becker et al, 1994; Maesawa et al, 1995), inactivation of the mismatch repair gene hMLH1 associated with microsatellite instability (MSI) (Fang et al, 2003), and hypermethylation of p16 have been repeatedly reported (Oue et al, 2002; Ding et al, 2003). As shown in these reports, studies have attempted to identify the biological factors involved in the malignant potential of gastric cancer. However, in clinical settings, only a few genes have been

${ }^{*}$ Correspondence: Dr S Komatsu; E-mail: skomatsu@koto.kpu-m.ac.jp
${ }^{3}$ These authors contributed equally to this work.

Revised 11 December 2012; accepted 22 January 2013; published online 19 February 2013

(C) 2013 Cancer Research UK. All rights reserved 0007-0920/13 
assayed as therapeutic targets and/or diagnostic biomarkers (Bang et al, 2010), suggesting that novel genes associated with the progression of gastric cancer need to be identified.

Recently, YWHAZ has been identified as a clinically relevant prognostic marker for breast cancer, lung cancer, and head and neck cancer (Fan et al, 2007; Matta et al, 2008; Lu et al, 2009; Neal et al, 2009) and could allow for the identification of patients with a potentially poor prognosis to receive more aggressive treatment. Moreover, it has been reported that YWHAZ can be posttranscriptionally regulated by microRNA miR-375 in vitro, leading to reductions in cell growth in gastric cancer cell lines (Tsukamoto et al, 2010). However, to date, there has been no report on the clinical and prognostic significance of YWHAZ in patients with primary gastric cancer. These findings prompted us to determine the clinicopathological and prognostic significance of YWHAZ overexpression/activation in primary gastric cancer.

Consequently, we demonstrated that YWHAZ was frequently overexpressed in gastric cancer lines and primary gastric cancers. The overexpression of YWHAZ was a poor prognosticator independent of other prognostic factors. Moreover, downregulation of YWHAZ expression was demonstrated to suppress cell proliferation, migration, and invasion in gastric cancer cell lines, and the overexpression of YWHAZ may be significantly associated with the lower expression of miR-375 seen in primary samples. Our results provided evidence that YWHAZ may be an important molecular marker for determining malignant properties and a target for molecular therapy in patients with gastric cancer.

\section{MATERIALS AND METHODS}

Gastric cancer cell lines and primary tissue samples. A total of seven gastric cancer cell lines such as KatoIII, NUGC4, HGC27, MKN7, MKN28, MKN45, and MKN74 were used. HGC27 cells were cultured in Dulbecco's Minimum Essential Medium (DMEM): F12 medium and the others were cultured in Roswell Park Memorial Institute (RPMI)-1640 medium (Sigma, St. Louis, MO, USA). All media were purchased from Sigma, and supplemented with $100 \mathrm{mll}^{-1}$ FBS (Trace Scientific, Melbourne, Australia). All cell lines were cultured in $50 \mathrm{mll}^{-1}$ carbon dioxide at $37^{\circ} \mathrm{C}$ in a humidified chamber. Primary tumour samples of gastric cancer had been obtained from 109 consecutive gastric cancer patients who underwent curative gastrectomy (R0) at the Division of Digestive Surgery, Department of Surgery, Kyoto Prefectural University of Medicine (Kyoto, Japan) between 2001 and 2003, and were embedded in paraffin after $24 \mathrm{~h}$ of formalin fixation. Relevant clinical and survival data were available for all patients. Written consent was always obtained in a formal styleafter approval by the local Ethics Committee. None of these patients underwent endoscopic mucosal resection, palliative resection, preoperative chemotherapy, or radiotherapy, and none of them had synchronous or metachronous multiple cancers in other organs. Disease stage was defined in accordance with the International Union against Cancer Tumour-lymph node-metastases (TNM) classification (7th edition SobinLH, Wittekind (2009)). The median follow-up period for surviving patients was 54.6 months (ranging from 0.5-66.7 months).

Western blotting. Anti-YWHAZ rabbit polyclonal antibody and anti-GAPDH antibody were purchased from Santa Cruz Biotechnology (Santa Cruz, CA, USA). YWHAZ antibody is an affinitypurified rabbit polyclonal antibody raised against a peptide mapping within a relatively divergent domain of YWHAZ. Cells were lysed and their proteins were extracted by M-PER Mammalian Protein Extraction Reagent (Thermo Scientific, Rockford, IL, USA). We used the MKN74 cell line as a positive control as its strong protein expression has been reported previously (Tsukamoto et al, 2010).

Immunohistochemistry. Tumour samples were fixed with $10 \%$ formaldehyde in PBS, embedded in paraffin, sectioned into $5-\mu \mathrm{m}$ thick slices, and subjected to immunohistochemical staining of the YWHAZ protein with the avidin-biotin-peroxidase method as described by Naoi et al (Naoi et al, 2008).

In brief, after deparaffinization, endogenous peroxidases were quenched by incubating the sections for $20 \mathrm{~min}$ in $3 \% \mathrm{H}_{2} \mathrm{O}_{2}$. Antigen retrieval was performed by heating the samples in $10 \mathrm{mmoll}^{-1}$ citrate buffer ( $\mathrm{pH} 6.0$ ) at $95^{\circ} \mathrm{C}$ for $60 \mathrm{~min}$. After treatment with Block Ace (Dainippon Sumitomo Pharmaceutical, Osaka, Japan) for $30 \mathrm{~min}$ at room temperature, sections were incubated at $4{ }^{\circ} \mathrm{C}$ overnight with an anti-YWHAZ (1:500) antibody. The avidin-biotin-peroxidase complex system (Vectastain Elite ABC universal kit; Vector Laboratories Inc., Burlingame, CA, USA) was used for colour development with diaminobenzidine tetrahydrochloride. Slides were counterstained with Mayer's hematoxylin. A formalin-fixed gastric cancer cell line overexpressing YWHAZ (MKN28), in which $>50 \%$ of cells showed staining of each protein, was used as a positive control, whereas a formalinfixed gastric cancer cell line with low expression of YWHAZ (HGC27) and MKN28 staining without the YWHAZ antibody was included as a negative control. For scoring YWHAZ expression, the intensity (intensity score: $0=$ negative, $1=$ weak, $2=$ moderate, and $3=$ strong) and percentage of the total cell population (proportion score: $0<10 \%, 10 \% \leqslant 1 \leqslant 33 \%, \quad 34 \% \leqslant 2 \leqslant 66 \%$, $67 \% \leqslant 3 \leqslant 100 \%)$ that expressed YWHAZ was evaluated for each case. In primary cases, YWHAZ protein expression was negative in most of the non-tumorous gastric mucosa and stroma. In all cases analysed, cases showing the negative expression as non-tumorous gastric mucosa and stroma were regarded as intensity score 0 , whereas cases showing the strongest YWHAZ protein expression were regarded as intensity score 3 . The remaining cases were divided into intensity score 1 and 2, respectively, according to the level of YWHAZ protein expression. The expression of YWHAZ was regarded as high expression (intensity plus proportion scores $\geqslant 4$ of tumour cells showing immunopositivity) or low expression (intensity plus proportion scores $\leqslant 3$ of tumour cells showing immunopositivity) using high-powered $(\times 200)$ microscopy (Tsuda, 2008). The expression of YWHAZ was evaluated considering the status of both cytoplasm and nucleus expression. If YWHAZ protein expression was recognised in both the cytoplasm and nucleus, the level of higher protein expression status in the cytoplasm and nucleus was employed. Morever, if YWHAZ protein expression was recognised in either the cytoplasm or nucleus, the level of its protein expression was employed.

Loss-of-function by small interfering RNA (siRNA) and cell growth analysis. For knocking down endogenous YWHAZ expression, each of the small interfering RNA (siRNAs) targeting YWHAZ (Stealth RNAi siRNA no. HSS111442, no. HSS111443, and no HSS111444; Invitrogen, Carlsbad, CA, USA) or a negative control (Negative universal control Med, Invitrogen) was transfected into cells $\left(10 \mathrm{nmoll}^{-1}\right)$ using Lipofectamine RNAiMAX (Invitrogen) according to the manufacturer's instructions. Knockdown of the YWHAZ gene was confirmed by western blotting. For measurements of cell growth, the number of viable cells at various time points after transfection was assessed by the colorimetric water-soluble tetrazolium salt (WST) assay (Cell counting kit-8; Dojindo Laboratories, Kumamoto, Japan) (Komatsu et al, 2009).

Transwell migration and invasion assays. Transwell migration and invasion assays were carried out in 24-well modified Boyden chambers (transwell-chamber, BD Transduction, Franklin Lakes, NJ, USA). The upper surface of $6.4-\mathrm{mm}$ diameter filters with $8 \mu \mathrm{m}$ 
pores was precoated with (invasion assay) or without (migration assay) Matrigel (BD Transduction). siRNA transfectants $\left(2 \times 10^{4}\right.$ cells per well) were transferred into the upper chamber. Following $48 \mathrm{~h}$ of incubation, migrated or invasive cells on the lower surface of filters were fixed and stained with the Diff-Quik stain (Sysmex, Kobe, Japan), and stained cell nuclei were counted directly in triplicate. We assessed the invasive potential by calculating the number of cells, which is the ratio of the percentage invasion through the Matrigel-coated filters relative to migration through the uncoated filters of test cells over that in the control counterparts.

Tissue RNA extraction and protocol for the detection of microRNAs. For formalin-fixed paraffin-embedded tissues, total RNA was extracted from four slices $15-\mu \mathrm{m}$ thick (total thickness of $60 \mu \mathrm{m})$ using a RecoverAll Total Nucleic Acid Isolation Kit (Ambion, Carlsbad, CA, USA), and eluted into $60 \mu \mathrm{l}$ of Elution Solution according to the manufacturer's instructions. The amounts of miRNAs were quantified in duplicate via qRT-PCR using human TaqMan MicroRNA Assay Kits (Applied Biosystems, Foster City, CA, USA). The reverse transcription reaction was carried out with a TaqMan MicroRNA Reverse Transcription Kit (Applied Biosystems) in $15 \mu \mathrm{l}$ containing $5 \mu \mathrm{l}$ of RNA extract, $0.15 \mu \mathrm{l}$ of $100 \mathrm{~mm}$ dNTPs, $1 \mu \mathrm{l}$ of Multiscribe Reverse Transcriptase $\left(50 \mathrm{U}^{-1} \mathrm{l}^{-1}\right), 1.5 \mu \mathrm{l}$ of $10 \times$ Reverse Transcription Buffer, $0.19 \mu \mathrm{l}$ of RNase inhibitor $\left(20 \mathrm{U}_{\mu} \mathrm{l}^{-1}\right), 3 \mu \mathrm{l}$ of gene-specific primer, and $4.16 \mu \mathrm{l}$ of Nuclease-free water. For the synthesis of cDNA, the reaction mixtures were incubated at $16^{\circ} \mathrm{C}$ for $30 \mathrm{~min}$, at $42{ }^{\circ} \mathrm{C}$ for $30 \mathrm{~min}$, at $85^{\circ} \mathrm{C}$ for $5 \mathrm{~min}$, and then held at $4{ }^{\circ} \mathrm{C}$. Next, $1.33 \mu \mathrm{l}$ of cDNA solution was amplified using $10 \mu \mathrm{l}$ of TaqMan $2 \times$ Universal PCR Master Mix with no AmpErase UNG (Applied Biosystems), $1 \mu \mathrm{l}$ of gene-specific primers/probe, and $7.67 \mu \mathrm{l}$ of Nuclease-free water in a final volume of $20 \mu \mathrm{l}$. Quantitative PCR was run on a 7300 Real-time PCR system (Applied Biosystems) and the reaction mixtures were incubated at $95^{\circ} \mathrm{C}$ for $10 \mathrm{~min}$, followed by 40 cycles of $95^{\circ} \mathrm{C}$ for $15 \mathrm{~s}$ and $60^{\circ} \mathrm{C}$ for $1 \mathrm{~min}$. Cycle threshold (Ct) values were calculated with SDS 1.4 software (Applied Biosystems). The expression of miRNAs from tissue samples was normalised using the $2-\Delta \Delta \mathrm{CT}$ method relative to U6 small nuclear RNA (RNU6B).

Statistical analysis. The clinicopathological variables pertaining to the corresponding patients were analysed for significance by the $\chi^{2}$ or Fisher's exact test. For the analysis of survival, Kaplan-Meier survival curves were constructed for groups based on univariate predictors and differences between the groups were tested with the log-rank test. Univariate and multivariate survival analyses were performed using the likelihood ratio test of the stratified Cox proportional hazards model. Differences between subgroups were tested with the non-parametric Mann-Whitney $U$-test. Differences were assessed with a two-sided test and considered significant at the $P<0.05$ level.

\section{RESULTS}

Protein expression of YWHAZ in gastric cancer cell lines. Western blotting analysis was performed using a YWHAZ-specific antibody (Figure 1A) to test how much of the YWHAZ protein was expressed in seven gastric cancer cells such as KatoIII, NUGC4, HGC27, MKN7, MKN28, MKN45, and MKN74. YWHAZ overexpression was observed in almost all cells except for the HGC27 cell line (six out of seven lines, $85.7 \%$ ), suggesting that this gene is a target for activation in gastric cancer cell lines.

A formalin-fixed gastric cancer MKN45 cell line presenting the overexpression of YWHAZ, in which $>50 \%$ of cells showed staining, was used as a positive control, whereas a formalin-fixed gastric cancer HGC27 cell line (data not shown) and MKN45
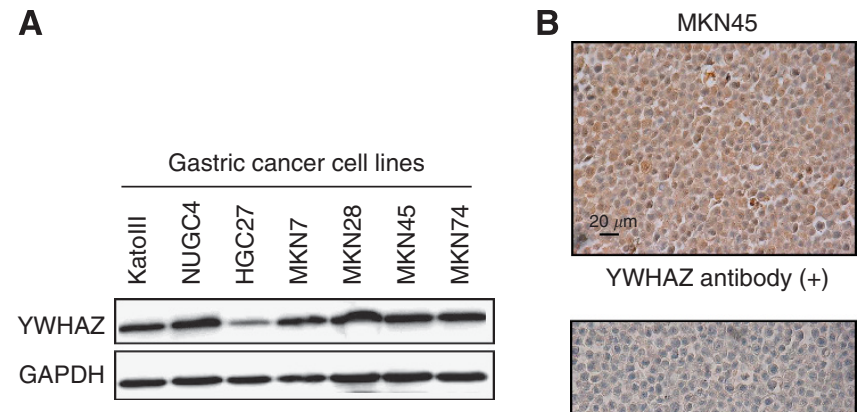

YWHAZ antibody (+)

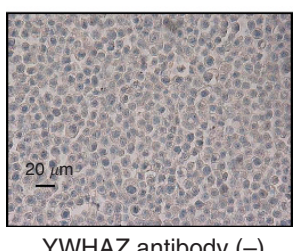

Figure 1. (A) Western blotting analysis using the YWHAZ-specific antibody to test how much YWHAZ protein is expressed in seven gastric cancer cells such as KatollI, NUGC4, HGC27, MKN7, MKN28, MKN45, and MKN74. (B). A formalin-fixed gastric cancer MKN45 cell line presenting overexpression of $\mathrm{YWHAZ}$, in which $>50 \%$ of cells showed staining, was used as a positive control, whereas MKN45 staining without the YWHAZ antibody presenting low expression of YWHAZ was included as a negative control.

staining without the YWHAZ antibody presenting low expression of YWHAZ was included as a negative control (Figure 1B).

Immunohistochemical analysis of YWHAZ expression in the primary tumours of gastric cancer. As the YWHAZ protein was overexpressed in some gastric cancer cell lines, it was hypothesised that YWHAZ was also highly expressed in gastric cancer tissues and assumed to be part of carcinogenesis and malignant outcomes. The clinicopathological significance of YWHAZ expression was examined in primary tumour samples of gastric cancer based on the immunohistochemical staining pattern of this protein. Specific immunostaining of the YWHAZ protein in primary samples was confirmed using cell lines as positive or negative controls (Figure 2A). Expression of the YWHAZ protein was observed in both the cytoplasm and nucleus of cancer cells. We classified 141 gastric cancer tumours into positive and negative groups according to the intensity and proportion of YWHAZ staining among tumour cells as described in the Materials and Methods. In primary cases, YWHAZ protein expression was negative in most of the non-tumorous gastric mucosal cell population (intensity score 0) and weakly positive in the gastric fundic gland. Supplementary Table 1 shows the distribution of patients with YWHAZ immunoreactivity in tumour cells according to the extent of intensity and proportion. Kaplan-Meier survival estimates showed that YWHAZ immunoreactivity in tumour cells was significantly associated with a worse overall survival according to the extent of the intensity and proportion (Figures 2C, 2D). In the total scores of the intensity plus proportion, the high expression group of YWHAZ, presenting scores $\geqslant 4$ of tumour cells showing immunopositivity, significantly presented poorer prognosis than the low expression group ( $P=0.0018$, log-rank test) (Figure $2 \mathrm{~B})$. Concerning separate analyses of YWHAZ protein expression between the cytoplasm and nucleus, as shown in Supplementary Figure $1 \mathrm{~A}$ and $1 \mathrm{~B}$, high expression of the YWHAZ protein in the cytoplasm $(P=0.0461$, log-rank test $)$ was associated more with poor prognosis than that in the nucleus ( $P=0.4049$, log-rank test). According to our results, expression of the YWHAZ protein in the cytoplasm may have a pivotal role on malignant outcomes in patients with gastric cancer. 
A Non-tumorous Gastric cancer (intensity score)

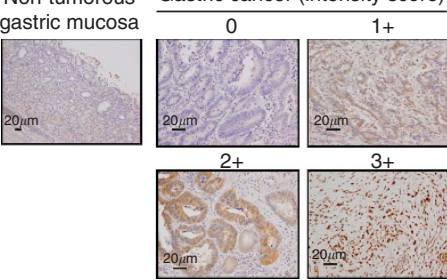

C

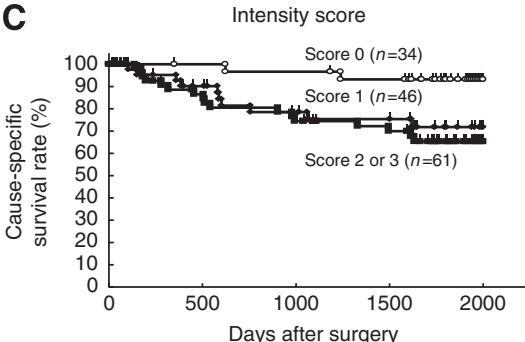

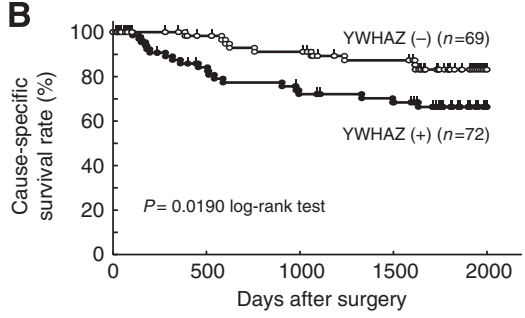

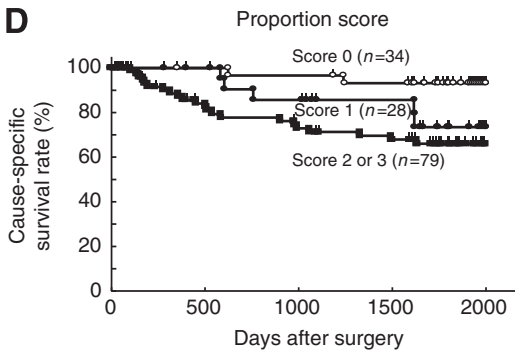

Figure 2. (A) Specific immunostaining of the YWHAZ protein in primary samples was confirmed. Expression of the YWHAZ protein was observed in both the cytoplasm and nucleus of cancer cells. For scoring YWHAZ expression, the intensity was scored as follows: $0=$ negative, $1=$ weak, 2 = moderate, 3 = strong. (B) In the total scores of intensity plus proportion, the high expression group of $Y W H A Z$, presenting scores $>4$ of tumour cells showing immunopositivity, presented significantly poorer prognosis than the low expression group $(P=0.0190$, log-rank test). Kaplan-Meier survival estimates showed that YWHAZ immunoreactivity in tumour cells was significantly associated with a worse overall survival according to the extent of intensity $(\mathbf{C})$ and proportion (D).

Association between YWHAZ protein levels and clinicopathological characteristics in primary cases of gastric cancer. The relationship between expression of the YWHAZ protein and clinicopathological characteristics is summarised in Table 1. Protein expression of YWHAZ was significantly associated with larger tumour size, venous invasion, lymphatic invasion, deeper depth of invasion, and higher pathological stage and recurrence rate, whereas other characteristics including histological grade were not. In the Cox proportional hazard regression model (Table 2), univariate analyses demonstrated that YWHAZ protein expression, age, location, tumour size, venous invasion, lymphatic invasion, $\mathrm{pT}$ category, $\mathrm{pN}$ category, and the stage of TNM classification were significantly associated with cause-specific survival. When the data were stratified for multivariate analysis using both forward and backward stepwise Cox regression procedures, YWHAZ immunoreactivity in tumour cells remained significant at $P<0.05$ (hazard ratio, 2.3 (1.003-5.304)) for overall survival in all patients, suggesting that immunoreactivity is an independent predictor of overall survival.

Suppression of cell proliferation by downregulation of YWHAZ expression. To gain insight into the potential role of YWHAZ as an oncogene whose overexpression could be associated with gastric carcinogenesis, we first performed a cell proliferation assay using siRNA specific to YWHAZ to investigate whether knockdown of YWHAZ expression could suppress the proliferation of gastric cancer cells showing overexpression of the gene. In the MKN74 and MKN28 cell lines, expression of the YWHAZ protein was efficiently knocked down 24-72 h after transient introduction of a YWHAZ-specific siRNA (siRNA-YWHAZ) over a control siRNA (siRNA-control) (Figure 3A). The proliferation of MKN74 and MKN28 cells was significantly lower than those of controls by 42.1 and $28.7 \%$, respectively, after the knockdown of endogenous YWHAZ expression.

Suppression of cell migration and invasion by downregulation of YWHAZ expression. Next, a Matrigel invasion assay was performed to examine the invasive potential of MKN74 (data not shown) and MKN28 cells (Figure 3B) transfected with siRNAYWHAZ. The number of cells that migrated through the uncoated (migration assay) or Matrigel-coated (invasion assay) membrane into the lower chamber was significantly lower in siRNA-YWHAZ transfected cells than in siRNA-control transfected cells, suggesting that YWHAZ has an invasive potential in gastric cancer cells.

Evaluation of whether miR-375 expression is associated with the extent of YWHAZ immunoreactivity in primary gastric cancer tumours. As shown in a previous report, tumour-suppressive miR-375 is downregulated in gastric cancer tumours and regulates cell survival by targeting YWHAZ in gastric cancer cell lines (Tsukamoto et al, 2010). However, it remains unknown whether miR-375 expression is associated with the extent of YWHAZ immunoreactivity in primary gastric cancer tumours. As a result, the expression of miR-375 in 10 tumours with overexpression of the YWHAZ protein was significantly lower than that in 10 tumours with low expression of the YWHAZ protein $(P=0.0047$, Figure 3C).

\section{DISCUSSION}

The YWHAZ gene, which encodes the $14-3-3 \zeta$ protein, is located on chromosome $8 \mathrm{q} 22.3$ and this area is frequently amplified in breast and other cancers (Pollack et al, 2002; Garnis et al, 2004). YWHAZ is included in the 14-3-3 family of proteins, which are a family of evolutionarily highly conserved acidic proteins expressed in all eukaryotic organisms (Aitken, 2006). Moore and Perez first discovered 14-3-3 in 1967 when they fractionated soluble proteins from brain tissue (Moore et al, 1968). In mammals, there are seven distinct isoforms: $\beta, \gamma, \varepsilon, \zeta, \eta, \sigma$, and $\tau$ that are encoded by seven different genes. 14-3-3 proteins have been found to interact with target proteins involved in the regulation of multiple cellular processes, such as cell cycle control, protein trafficking, antiapoptosis, metabolism, signal transduction, inflammation, and cell adhesion/motility (Wilker and Yaffe, 2004; Morrison, 2009).

YWHAZ has been identified as a clinically relevant prognostic marker for breast cancer (Lu et al, 2009; Neal et al, 2009), lung cancer (Fan et al, 2007), and head and neck cancer (Matta et al, 2008) and may allow for the identification of patients whose 
Table 1. Association between clinicopathologic characteristics and YWHAZ expression

YWHAZ immunoreactivity

\begin{tabular}{l|c|c|c|c|}
\hline & $\mathbf{n}$ & High expression & Low expression & $\boldsymbol{P}^{\text {-value }}$ \\
\hline Total & 141 & 72 & 69 & \\
\hline Sex & 94 & $51(71 \%)$ & $43(62 \%)$ & $26(38 \%)$ \\
\hline Male & 47 & $21(29 \%)$ & 0.2836 \\
Female & 9
\end{tabular}

Age (year)

Mean
$<60$

63 (range: 27-89)

$\geqslant 60$

\section{Location}

Upper

Middle

Lower

\begin{tabular}{l|l}
20 & $13(18 \%)$ \\
71 & $36(50 \%)$ \\
50 & $23(32 \%)$
\end{tabular}

\section{7 (10\%)}

35 (51\%)

27 (39\%)

0.5014

\section{Histopathological grading}

Differentiated

Undifferentiated

69

72

40 (56\%)

32 (44\%)

$29(42 \%)$

$40(58 \%)$

0.1082

\section{Tumour size ( $\mathrm{mm}$ )}

$<35$
$\geqslant 35$

74

67

31 (43\%)

41 (57\%)

43 (62\%)

$26(38 \%)$

0.0220

\section{Venous invasion}

0

$1-3$

98

98
43

42 (58\%)

30 (42\%)

$56(81 \%)$

$13(19 \%)$

0.0032

Lymphatic invasion

0

$1-3$

\begin{tabular}{l|l}
75 & $31(43 \%)$
\end{tabular}

$66 \quad 41(57 \%)$

$44(64 \%)$

$25(36 \%)$

0.0137

\section{PT categories}

pT1

PT2

pT3

pT4

\begin{tabular}{c|c}
78 & $30(42 \%)$ \\
11 & $5(7 \%)$ \\
23 & $17(24 \%)$ \\
29 & $20(27 \%)$
\end{tabular}

$48(70 \%)$

$6(9 \%)$

$6(9 \%)$

$9(12 \%)$

0.0095

\section{$\mathrm{pN}$ categories}

\begin{tabular}{|l|l}
\hline N0 & 92 \\
N1 & 17 \\
N2 & 10 \\
N3 & 22 \\
\hline
\end{tabular}

\begin{tabular}{l|c}
92 & $40(56 \%)$ \\
17 & $11(15 \%)$ \\
10 & $5(7 \%)$ \\
22 & $16(22 \%)$
\end{tabular}

\section{$52(75 \%)$}

$6(9 \%)$

$5(7 \%)$

$6(9 \%)$
0.1227

\section{p stage}

\begin{tabular}{|l|r}
\hline I & 86
\end{tabular}

II 17

III

\section{Recurrence}

Absent

Present

111

30

$51(71 \%)$

$21(29 \%)$
$53(77 \%)$

$6(9 \%)$

$10(14 \%)$
0.0017

Note: significant values are in boldface type. ${ }^{*} P$-values are from $\chi^{2}$ or Fisher's exact test and were significant at $<0.05$.

tumours are resistant to standard chemotherapies to receive more aggressive treatment (Frasor et al, 2006; Li et al, 2010). YWHAZ has been implicated in the initiation and progression of cancer and has been shown to be overexpressed in multiple cancer tissues and cell lines such as oesophageal cancer (Sharma et al, 2003), pancreatic cancer (Shen et al, 2004), colon cancer (Lu et al, 2007), and oral cancer (Arora et al, 2005), even if gene amplification was not always detected. Mechanisms independent 
Table 2. Multivariate analysis using the stepwise Cox regression procedures

\begin{tabular}{|c|c|c|c|c|}
\hline \multirow[b]{2}{*}{ Variables } & \multirow{2}{*}{$\begin{array}{c}\text { Univariate }^{\mathrm{a}} \\
\boldsymbol{P} \text {-value }\end{array}$} & \multicolumn{3}{|c|}{ Multivariate $^{\mathrm{b}}$} \\
\hline & & HR & $95 \% \mathrm{Cl}$ & $\boldsymbol{P}$-value \\
\hline \multicolumn{5}{|l|}{ Sex } \\
\hline Male vs female & 0.8064 & 2.673 & $1.098-6.504$ & 0.0302 \\
\hline \multicolumn{5}{|l|}{ Age } \\
\hline$\geqslant 60$ vs $<60$ & 0.0243 & 2.841 & $1.121-7.194$ & 0.0277 \\
\hline \multicolumn{5}{|l|}{ Location } \\
\hline U vs ML & 0.0370 & & - & \\
\hline \multicolumn{5}{|l|}{ Histological type } \\
\hline $\begin{array}{l}\text { Undifferentiated vs } \\
\text { differentiated }\end{array}$ & 0.9078 & & - & \\
\hline \multicolumn{5}{|l|}{ Tumour size $(\mathrm{mm})$} \\
\hline$\geqslant 35$ vs $<35$ & $<0.0001$ & & - & \\
\hline \multicolumn{5}{|l|}{ Venous invasion } \\
\hline Positive vs negative & $<0.0001$ & 2.865 & $1.183-6.944$ & 0.0195 \\
\hline \multicolumn{5}{|c|}{ Lymphatic invasion } \\
\hline Positive vs negative & $<0.0001$ & & - & \\
\hline \multicolumn{5}{|l|}{ pT-stage } \\
\hline T3-4 vs T1-2 & $<0.0001$ & 20.833 & $2.577-166.667$ & 0.0044 \\
\hline \multicolumn{5}{|l|}{$\mathrm{pN}$-stage } \\
\hline $\mathrm{N} 2-3$ vs N0-1 & $<0.0001$ & 7.692 & $2.770-21.28$ & $<0.0001$ \\
\hline \multicolumn{5}{|c|}{ YWHAZ expression } \\
\hline High vs low & 0.0190 & 2.307 & $1.003-5.304$ & 0.0491 \\
\hline $\begin{array}{l}\text { Abbreviations: } \mathrm{Cl}=\mathrm{con} \\
\mathbf{a}_{\text {The Kaplan-Meier me }} \\
\mathbf{b}_{\text {Multivariate survival ar }}\end{array}$ & $\begin{array}{l}\text { rd ratio. No } \\
\text { determinec }\end{array}$ & ooldface & & \\
\hline
\end{tabular}

of the increased gene copy number, such as the modulation of gene transcription, protein translation, or RNA and protein stability may also contribute to increased protein expression. These findings prompted us to determine the clinicopathological and prognostic significance of YWHAZ overexpression/activation in primary gastric cancer. However, to date, there has been no report on the clinical significance of YWHAZ in patients with primary gastric cancer.

In the present study, it was hypothesised that the overexpression/activation of YWHAZ may promote tumour cell proliferation and/or survival in gastric cancer. To test this hypothesis, we examined the expression status of YWHAZ and the clinicopathological, as well as biological significance of its expression in cell lines and primary tumours of gastric cancer. Consequently, it was demonstrated that YWHAZ was frequently overexpressed in 51\% (72/141) of gastric cancer patients and this overexpression was a poor prognosticator independent of other prognostic factors. The prognosis of gastric cancer patients was involved in both the intensity and proportion of YWHAZ activity in an expression-dependent manner. In addition, downregulation of YWHAZ expression suppressed cell proliferation, migration, and invasion in gastric cancer cell lines, although several previous studies reported similar results in other cancers. Namely, the overexpression of YWHAZ in breast cancer cell lines enhanced anchorage-independent growth and inhibited stress-induced apoptosis, whereas downregulation of YWHAZ reduced anchorage-independent growth and sensitised cells to stress-induced apoptosis (Neal et al, 2009). Also, in lung cancer, knockdown of YWHAZ sensitised cells to stress-induced apoptosis and enhanced cell adhesion and cell-cell contacts (Li et al, 2008; Niemantsverdriet et al, 2008).

The significance of YWHAZ overexpression in gastric cancers remains unknown. In this study, we also determined the expression of tumour-suppressive microRNA miR-375 in primary gastric tumours based on the extent of YWHAZ expression. It has been reported that YWHAZ can be post-transcriptionally regulated by microRNA miR-375 in vitro, leading to the downregulation of both YWHAZ mRNA and protein, effectively altering the available pool of YWHAZ and reducing cell growth in gastric cancer cell lines (Tsukamoto et al, 2010). However, in primary samples, the association between YWHAZ and miR-375 has been not reported and remains unknown. As a result, we confirmed that the higher 
A

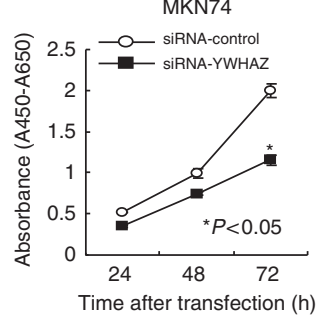

MKN28

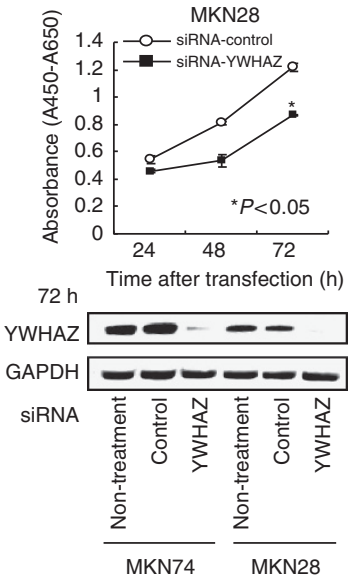

B
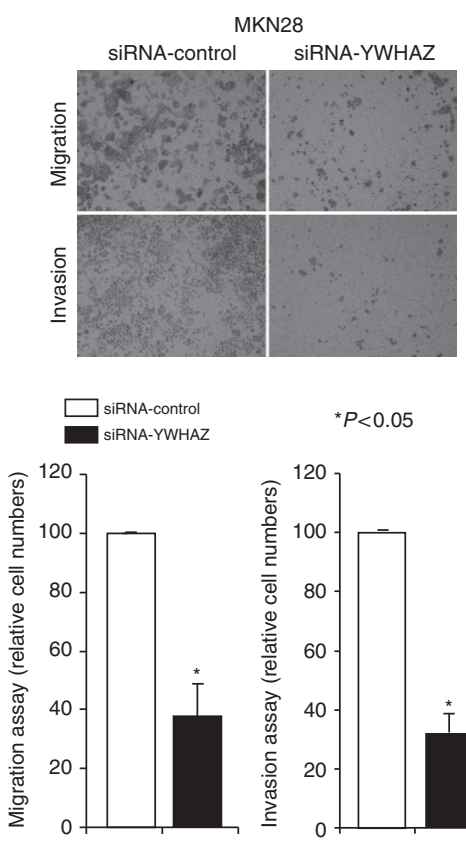

C

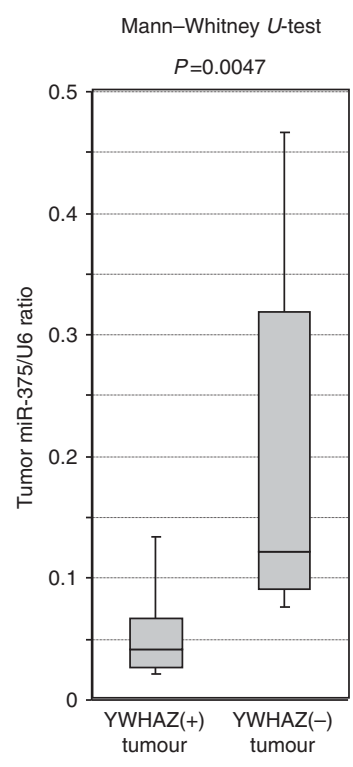

Figure 3. (A) Loss-of-function screening was done using small interfering RNAs targeting YWHAZ in MKN74 and MKN28 cells. The knockdown of a target gene was confirmed by western blotting. For measurements of cell growth, the number of viable cells at various time points after transfection was assessed by the colorimetric water-soluble tetrazolium salt (WST) assay. (B) Transwell migration and invasion assays.

(C) Evaluation of whether miR-375 expression is associated with the extent of YWHAZ immunoreactivity in primary gastric cancer tumours.

expression of the YWHAZ protein was significantly associated with the lower expression of miR-375 in primary samples. This result implies that epigenetic regulation through microRNAs is one of the mechanisms for the overexpression of YWHAZ in primary gastric cancer.

Other fascinating reports are that the overexpression of YWHAZ occurs in the premalignant hyperplastic stages of oral and oesophageal cancers (Bajpai et al, 2008; Matta et al, 2007; Ralhan et al, 2009) and in atypical ductal hyperplasia and ductal carcinoma in situ (DCIS) of breast cancer (Wulfkuhle et al, 2002; Danes et al, 2008). These findings suggested that YWHAZ may contribute to carcinogenesis and the development of early stage cancers. Moreover, YWHAZ overexpression was found to be a 'second hit' in a subset of ERBB2-overexpressing DCIS lesions facilitating the transition from noninvasive DCIS to life-threatening invasive breast cancer through the activated TGF- $\beta /$ Smads pathway leading to epithelial to mesenchymal transition (EMT) (Lu et al, 2009). Indeed, co-overexpression of YWHAZ and ERBB2 in breast cancers from patients was significantly correlated with distant metastasis, poor prognosis, and higher rates of recurrence in breast cancer patients ( $\mathrm{Lu}$ et al, 2009). In gastric cancer, overexpression of the ERBB2 protein, which was also shown as HER2, was associated with poor prognosis (Yonemura et al, 1991; Uchino et al, 1993). In addition, a recent study demonstrated that a monoclonal antibody against HER2, Trastuzumab, in combination with chemotherapy (ToGa study) can be considered as a new standard option for patients with HER2-positive advanced gastric cancer (Bang et al, 2010); moreover, this treatment contributes to survival prolongation. Therefore, YWHAZ may be a key molecule for selecting prospective patients with malignant outcomes associated with HER2 expression in this chemotherapy. This issue is currently being evaluated.

In conclusion, this is the first report demonstrating that YWHAZ has a pivotal oncogenic role and is a potential therapeutic target in gastric cancer. We showed frequent overexpression of the
YWHAZ protein and its prognostic value in patients with gastric cancer. Although studies of larger cohorts are needed to validate these findings before moving to a clinical setting, our results may provide the possibility that YWHAZ is an important molecular marker for determining malignant properties and targets for molecular therapy in patients with this lethal disease.

\section{REFERENCES}

Aitken A (2006) 14-3-3 proteins: a historic overview. Semin Cancer Biol 16(3): $162-172$.

Arora S, Matta A, Shukla NK, Deo SV, Ralhan R (2005) Identification of differentially expressed genes in oral squamous cell carcinoma. Mol Carcinog 42(2): 97-108

Bajpai U, Sharma R, Kausar T, Dattagupta S, Chattopadhayay TK, Ralhan R (2008) Clinical significance of 14-3-3 zeta in human esophageal cancer. Int J Biol Markers 23(4): 231-237.

Bang YJ, Van Cutsem E, Feyereislova A, Chung HC, Shen L, Sawaki A, Lordick F, Ohtsu A, Omuro Y, Satoh T, Aprile G, Kulikov E, Hill J, Lehle M, Ruschoff J, Kang YK (2010) Trastuzumab in combination with chemotherapy $v s$ chemotherapy alone for treatment of HER2-positive advanced gastric or gastro-oesophageal junction cancer (ToGA): a phase 3 , open-label, randomised controlled trial. Lancet 376(9742): 687-697.

Becker KF, Atkinson MJ, Reich U, Becker I, Nekarda H, Siewert JR, Hofler H (1994) E-cadherin gene mutations provide clues to diffuse type gastric carcinomas. Cancer Res 54(14): 3845-3852.

Danes CG, Wyszomierski SL, Lu J, Neal CL, Yang W, Yu D (2008) 14-3-3 zeta down-regulates p53 in mammary epithelial cells and confers luminal filling. Cancer Res 68(6): 1760-1767.

Ding Y, Le XP, Zhang QX, Du P (2003) Methylation and mutation analysis of p16 gene in gastric cancer. World J Gastroenterol 9(3): 423-426.

Fan T, Li R, Todd NW, Qiu Q, Fang HB, Wang H, Shen J, Zhao RY, Caraway NP, Katz RL, Stass SA, Jiang F. (2007) Up-regulation of 14-3-3zeta in lung cancer and its implication as prognostic and therapeutic target. Cancer Res 67(16): 7901-7906. 
Fang DC, Wang RQ, Yang SM, Yang JM, Liu HF, Peng GY, Xiao TL, Luo YH (2003) Mutation and methylation of hMLH1 in gastric carcinomas with microsatellite instability. World J Gastroenterol 9(4): 655-659.

Frasor J, Chang EC, Komm B, Lin CY, Vega VB, Liu ET, Miller LD, Smeds J, Bergh J, Katzenellenbogen BS (2006) Gene expression preferentially regulated by tamoxifen in breast cancer cells and correlations with clinical outcome. Cancer Res 66(14): 7334-7340.

Garnis C, Coe BP, Ishkanian A, Zhang L, Rosin MP, Lam WL (2004) Novel regions of amplification on $8 \mathrm{q}$ distinct from the MYC locus and frequently altered in oral dysplasia and cancer. Genes Chromosomes Cancer 39(1): 93-98.

Komatsu S, Imoto I, Tsuda H, Kozaki KI, Muramatsu T, Shimada Y, Aiko S, Yoshizumi Y, Ichikawa D, Otsuji E, Inazawa J (2009) Overexpression of SMYD2 relates to tumor cell proliferation and malignant outcome of esophageal squamous cell carcinoma. Carcinogenesis 30(7): 1139-1146.

Lee JH, Abraham SC, Kim HS, Nam JH, Choi C, Lee MC, Park CS, Juhng SW, Rashid A, Hamilton SR, Wu TT (2002) Inverse relationship between APC gene mutation in gastric adenomas and development of adenocarcinoma. Am J Pathol 161(2): 611-618.

Li Y, Zou L, Li Q, Haibe-Kains B, Tian R, Li Y, Desmedt C, Sotiriou C, Szallasi Z, Iglehart JD, Richardson AL, Wang ZC (2010) Amplification of LAPTM4B and YWHAZ contributes to chemotherapy resistance and recurrence of breast cancer. Nat Med 16(2): 214-218.

Li Z, Zhao J, Du Y, Park HR, Sun SY, Bernal-Mizrachi L, Aitken A, Khuri FR, Fu H (2008) Down-regulation of 14-3-3zeta suppresses anchorageindependent growth of lung cancer cells through anoikis activation. Proc Natl Acad Sci USA 105(1): 162-167.

Lu B, Xu J, Zhu Y, Zhang H, Lai M (2007) Systemic analysis of the differential gene expression profile in a colonic adenoma-normal SSH library. Clin Chim Acta 378(1-2): 42-47.

Lu J, Guo H, Treekitkarnmongkol W, Li P, Zhang J, Shi B, Ling C, Zhou X, Chen T, Chiao PJ, Feng X, Seewaldt VL, Muller WJ, Sahin A, Hung MC, Yu D (2009) 14-3-3zeta cooperates with ErbB2 to promote ductal carcinoma in situ progression to invasive breast cancer by inducing epithelial-mesenchymal transition. Cancer cell 163 : 195-207.

Maesawa C, Tamura G, Suzuki Y, Ogasawara S, Sakata K, Kashiwaba M, Satodate R (1995) The sequential accumulation of genetic alterations characteristic of the colorectal adenoma-carcinoma sequence does not occur between gastric adenoma and adenocarcinoma. J Pathol 176(3): 249-258.

Martin 2nd RC, Jaques DP, Brennan MF, Karpeh M (2002) Extended local resection for advanced gastric cancer: increased survival $v s$ increased morbidity. Ann Surg 236(2): 159-165.

Matta A, Bahadur S, Duggal R, Gupta SD, Ralhan R (2007) Over-expression of 14-3-3zeta is an early event in oral cancer. BMC Cancer 7: 169 .

Matta A, DeSouza LV, Shukla NK, Gupta SD, Ralhan R, Siu KW (2008) Prognostic significance of head-and-neck cancer biomarkers previously discovered and identified using iTRAQ-labeling and multidimensional liquid chromatography-tandem mass spectrometry. J Proteome Res 7(5): 2078-2087.

Moore BW, Perez VJ, Gehring M (1968) Assay and regional distribution of a soluble protein characteristic of the nervous system. J Neurochem 15(4): 265-272.

Morrison DK (2009) The 14-3-3 proteins: integrators of diverse signaling cues that impact cell fate and cancer development. Trends Cell Biol 19(1): 16-23.

Naoi Y, Miyoshi Y, Taguchi T, Kim SJ, Arai T, Maruyama N, Tamaki Y, Noguchi S (2008) Connexin26 expression is associated with aggressive phenotype in human papillary and follicular thyroid cancers. Cancer Lett 262(2): 248-256.

Neal CL, Yao J, Yang W, Zhou X, Nguyen NT, Lu J, Danes CG, Guo H, Lan KH, Ensor J, Hittelman W, Hung MC, Yu D (2009) 14-3-3zeta overexpression defines high risk for breast cancer recurrence and promotes cancer cell survival. Cancer Res 69(8): 3425-3432.

Niemantsverdriet M, Wagner K, Visser M, Backendorf C (2008) Cellular functions of 14-3-3 zeta in apoptosis and cell adhesion emphasize its oncogenic character. Oncogene 27(9): 1315-1319.

Oue N, Motoshita J, Yokozaki H, Hayashi K, Tahara E, Taniyama K, Matsusaki K, Yasui W (2002) Distinct promoter hypermethylation of p16INK4a, CDH1, and RAR-beta in intestinal, diffuse-adherent, and diffuse-scattered type gastric carcinomas. J Pathol 198(1): 55-59.

Park WS, Oh RR, Park JY, Lee SH, Shin MS, Kim YS, Kim SY, Lee HK, Kim PJ, Oh ST, Yoo NJ, Lee JY (1999) Frequent somatic mutations of the beta-catenin gene in intestinal-type gastric cancer. Cancer Res 59(17): 4257-4260.

Parkin DM, Bray F, Ferlay J, Pisani P (2005) Global cancer statistics, 2002. CA Cancer J Clin 55(2): 74-108.

Pollack JR, Sorlie T, Perou CM, Rees CA, Jeffrey SS, Lonning PE, Tibshirani R, Botstein D, Borresen-Dale AL, Brown PO (2002) Microarray analysis reveals a major direct role of DNA copy number alteration in the transcriptional program of human breast tumors. Proc Natl Acad Sci USA 99(20): 12963-12968.

Ralhan R, Desouza LV, Matta A, Chandra Tripathi S, Ghanny S, Dattagupta S, Thakar A, Chauhan SS, Siu KW (2009) iTRAQ-multidimensional liquid chromatography and tandem mass spectrometry-based identification of potential biomarkers of oral epithelial dysplasia and novel networks between inflammation and premalignancy. J Proteome Res 8(1): 300-309.

Sharma R, Samantaray S, Shukla NK, Ralhan R (2003) Transcriptional gene expression profile of human esophageal squamous cell carcinoma. Genomics 81(5): 481-488.

Shen J, Person MD, Zhu J, Abbruzzese JL, Li D (2004) Protein expression profiles in pancreatic adenocarcinoma compared with normal pancreatic tissue and tissue affected by pancreatitis as detected by two-dimensional gel electrophoresis and mass spectrometry. Cancer Res 64(24): 9018-9026.

SobinLH G, Wittekind Ch (2009) International Union Against Cancer (UICC) TNM Classification of Malignant Tumors. 7th edn.Oxford, UKWileyBlackwell.

Tsuda H (2008) Individualization of breast cancer based on histopathological features and molecular alterations. Breast Cancer (Tokyo, Japan) 15(2): 121-132.

Tsukamoto Y, Nakada C, Noguchi T, Tanigawa M, Nguyen LT, Uchida T, Hijiya N, Matsuura K, Fujioka T, Seto M, Moriyama M (2010) MicroRNA-375 is downregulated in gastric carcinomas and regulates cell survival by targeting PDK1 and 14-3-3zeta. Cancer Res 70(6): 2339-2349.

Uchino S, Tsuda H, Maruyama K, Kinoshita T, Sasako M, Saito T, Kobayashi M, Hirohashi S (1993) Overexpression of c-erbB-2 protein in gastric cancer. Its correlation with long-term survival of patients. Cancer 72(11): 3179-3184.

Ushijima T, Sasako M (2004) Focus on gastric cancer. Cancer cell 5(2): $121-125$.

Wilker E, Yaffe MB (2004) 14-3-3 proteins-a focus on cancer and human disease. J Mol Cell Cardiol 37(3): 633-642.

Wulfkuhle JD, Sgroi DC, Krutzsch H, McLean K, McGarvey K, Knowlton M, Chen S, Shu H, Sahin A, Kurek R, Wallwiener D, Merino MJ, Petricoin 3rd EF, Zhao Y, Steeg PS (2002) Proteomics of human breast ductal carcinoma in situ. Cancer Res 62(22): 6740-6749.

Yonemura Y, Ninomiya I, Yamaguchi A, Fushida S, Kimura H, Ohoyama S, Miyazaki I, Endou Y, Tanaka M, Sasaki T (1991) Evaluation of immunoreactivity for erbB-2 protein as a marker of poor short term prognosis in gastric cancer. Cancer Res 51(3): 1034-1038.

This work is published under the standard license to publish agreement. After 12 months the work will become freely available and the license terms will switch to a Creative Commons AttributionNonCommercial-Share Alike 3.0 Unported License.

Supplementary Information accompanies this paper on British Journal of Cancer website (http://www.nature.com/bjc) 